\title{
DESAIN DAN IMPLEMENTASI REMOTE TERMINAL UNIT (RTU) BERBASIS ARM CORTEX PADA SIMULATOR DISTRIBUSI AIR
}

\author{
Murie Dwiyaniti* dan Kendi Moro Nitisasmita \\ Jurusan Teknik Elektro, Politeknik Negeri Jakarta \\ J1 Prof.Dr.GA Siwabessy, Kampus Baru UI Depok 16425 \\ *Corresponding author, e-mail : muriedwiyaniti@yahoo.com
}

\begin{abstract}
Abstrak - Di industri, umumnya, pengendali peralatan dan instrumen pada field level menggunakan PLC. Namun PLC ini merupakan hak milik atau hak cipta (proprietary) suatu korporasi multinasional sehingga berpengaruh pada harga jual yang relatif mahal (costly). Alternatif pengendali adalah RTU berbasis mikrokontroler yang berbiaya murah, konsumsi daya rendah namun realibilitas tinggi dan dapat diaplikasikan di berbagai plant. Pada penelitian ini, dibuat RTU berbasis mikrokontroler ARM Cortex 32 bit XMC 4500 yang diaplikasikan sebagai pengendali simulator distribusi air. RTU ini mempunyai 8 input dan 6 output digital, 3 input dan 2 output analog. Hasilnya, RTU bekerja dengan baik sesuai dengan deskripsi kerja yang telah ditentukan sebelumnya. Hal ini ditandai dengan berfungsinya semua modul IO digital dan analog, modul komunikasi serial dan modul power supply.
\end{abstract}

Kata Kunci : RTU, ARM Cortex, XMC 4500, simulator distribusi air

\begin{abstract}
In industry, the control apparatus and instruments at the field level use a PLC in general. Unfortunately, PLC is a proprietary or copyright of a multinational corporation, which make their costs relatively expensive. Alternative controllers can be implemented based on RTU microcontrollers which are of low costs, low power consumption but have high reliability and can be applied in a variety of plants. In this research, RTU based on a microcontroller, 32-bit ARM Cortex XMC 4500, has been developed and applied as a controller of water distribution simulator. This RTU has 8 inputs and 6 outputs digital, 3 inputs and 2 outputs analog. The result shows that the RTU works properly in accordance to the specifications that had been predetermined. This has been proven by the proper functioning of all digital and analog IO modules, serial communication modules and power supply modules.
\end{abstract}

Keywords : RTU, ARM Cortex, XMC4500, water distribution simulator

Copyright $\odot 2016$ JNTE. All rights reserved

\section{PENDAHULUAN}

SCADA terdiri atas tiga (3) komponen penting yaitu Master Station atau Master Terminal Unit (MTU), Remote Terminal yang dapat diperankan oleh RTU atau PLC, dan komponen Communication Network (jaringan komunikasi) [1]. Komponen yang paling penting untuk mendukung SCADA adalah RTU/PLC. Tanpa RTU/PLC, SCADA tidak mampu bekerja.

Di industri sebagian besar sistem kontrol proses menggunakan RTU berbasis pada PLC. Tapi karena teknologi PLC adalah hak milik atau hak cipta dari perusahaan multinasional berdampak pada harga jual yang relatif mahal. Alternatif lain adalah menciptakan sebuah RTU berbasis mikrokontroler, sehingga akan menghasilkan RTU dengan biaya rendah, konsumsi daya rendah tapi keandalan tinggi.

Penelitian ini membuat prototipe RTU berbasis mikrokontroler 32-bit ARM Cortex (XMC 4500), yang diimplementasikan pada simulator distribusi air. RTU akan diuji dalam konektivitas tunggal (standalone). Kesuksesan dalam membuat RTU ini akan membuka peluang dan memberikan solusi alternatif untuk industri dalam penggunaan kontroler dengan harga murah.

\section{TINJAUAN PUSTAKA}

RTU yang sudah eksis baik yang telah memiliki hak cipta atau hak milik corporate, lembaga riset pemerintah atau swasta maupun yang dikembangkan institusi perguruan tinggi memiliki kesamaan arsitektur dasar namun 
berbeda dalam penggunaan prosesornya [2],[3],[4]. Arsitektur RTU memiliki konfigurasi berupa power supply, CPU (Central Processing Unit), Volatile Memory, NonVolatile Memory, modul analog input, modul analog output, modul digital input, modul digital output, dilengkapi dengan Central bus. Semua elemen di RTU dikendalikan oleh sebuah prosesor dalam hal ini mikrokontroler yang terletak di CPU.

Fungsi standar RTU adalah sebagai antarmuka untuk mengirimkan sinyal kontrol pada peralatan yang dikendalikan, mengambil data dari peralatan tersebut, dan mengirimkan data tersebut ke MTU [5]. Konfigurasi RTU dapat dilihat pada Gambar 1.

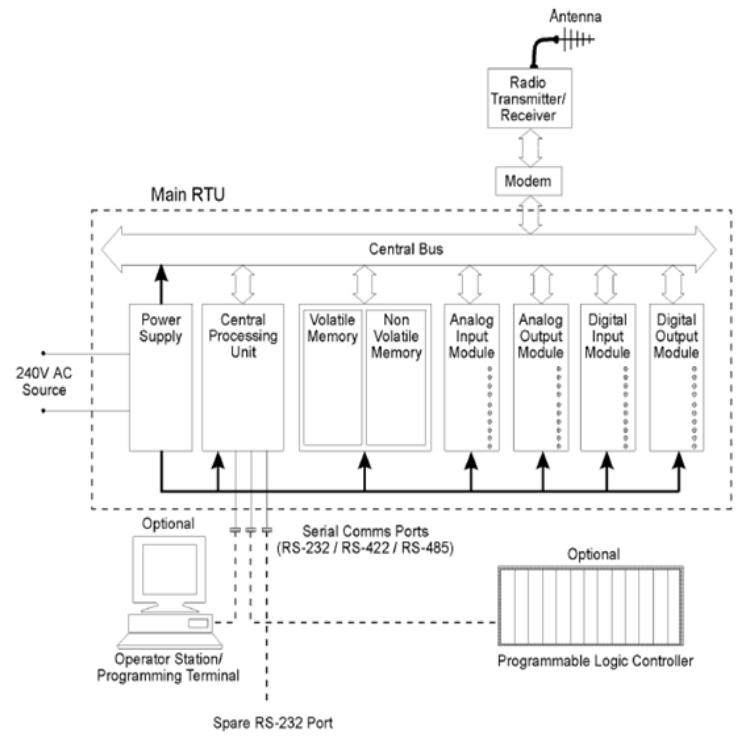

Gambar 1.Konfigurasi RTU [5]

RTU yang digunakan pada penelitian ini berbasiskan mikrokontroler ARM Cortex 32 Bit yang merupakan sebuah prosesor 32-bit dengan tipe RISC (Reduced Instruction Set Computer). Kelebihan mikrokontroler ini adalah kinerja yang sangat tinggi hingga $2 \mathrm{GHz}$, harga yang sangat murah dan hemat energi [6].

Komponen utama yang digunakan dalam membuat modul input digital adalah resistor dan optocoupler. Rangkaian tipikal input digital dapat dilihat pada Gambar 2.

Komponen utama Output digital pada RTU adalah optocoupler dan MOSFET (Metal Oxide Semiconductor Field Effect Transistor) tipe-N (NMOS). Pada penelitian ini, MOSFET dipilih karena mempunyai kelebihan dibanding dengan transistor BJT (Bipolar Junction Transistor), yaitu MOSFET mempunyai input impedansi yang sangat tinggi, menghasilkan disipasi daya yang rendah dan noise yang rendah. rangkaian tipikal output digital dapat dilihat pada Gambar 3.

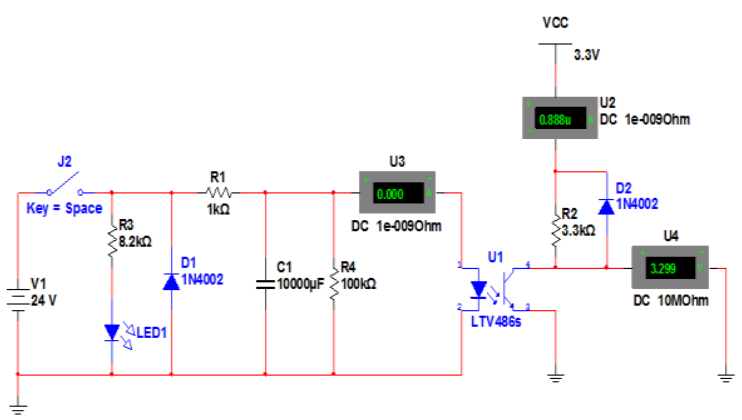

Gambar 2. Rangkaian input digital

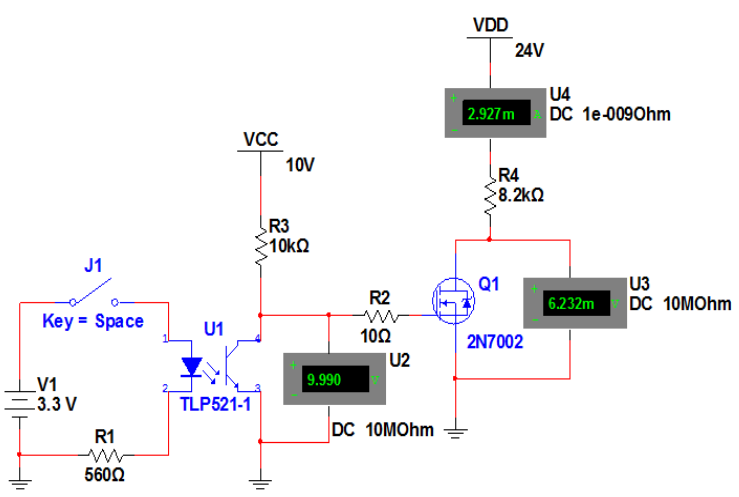

Gambar 3. Rangkaian output digital

Sedangkan untuk rangkaian IO analog, terdiri dari 3 IC, yaitu:

1. Converter $3,3 \mathrm{~V}$ ke $5 \mathrm{~V}$

2. DAC MCP4725

3. Sunyuan $0-5 \mathrm{~V}$ to $4-20 \mathrm{~mA}$

Fungsi dari konverter adalah sebagai jembatan penyambung antara mikrokontroler yang mempunyai tegangan $3,3 \mathrm{~V}$ dengan perangkat TTL dimana level tegangannya adalah $5 \mathrm{~V}$.

DAC berfungsi mengubah digital menjadi analog output $0-5 \mathrm{~V}$, rancangan ini di kendalikan oleh protocol I2C, sehingga mikrokontroler harus mengikuti protocol tersebut untuk dapat mengeluarkan signal 0-5V.

Sunyuan berfungsi mengubah tegangan analog 0-5V menjadi output arus 4-20mA. Gambar skematik rangkaian I/O analog dapat dilihat pada Gambar 4. 


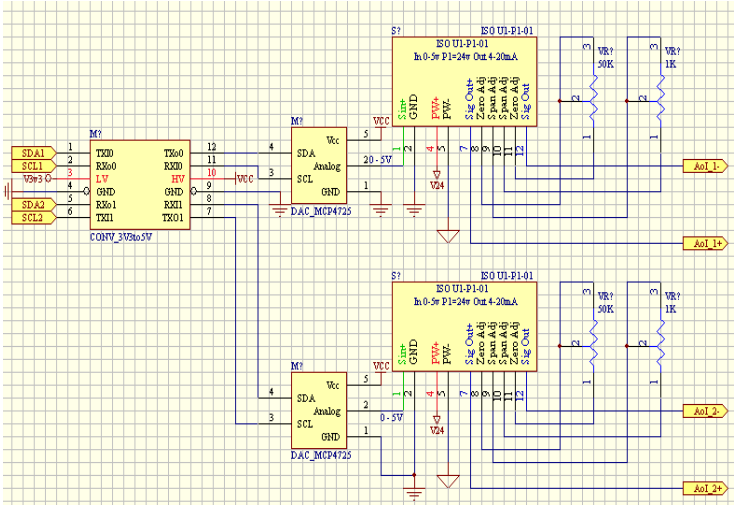

Gambar 4. Skematik rangkaian I/O analog

\section{METODOLOGI}

Kegiatan penelitian ini dilakukan di Laboratorium SCADA Teknik Listrik PNJ. Metode penelitian yang digunakan adalah metode eksperimen dengan cara membuat alat baru berupa RTU berbasis mikrokontroler. RTU ini diimplementasikan pada simulator distribusi air seperti pada Gambar 5.

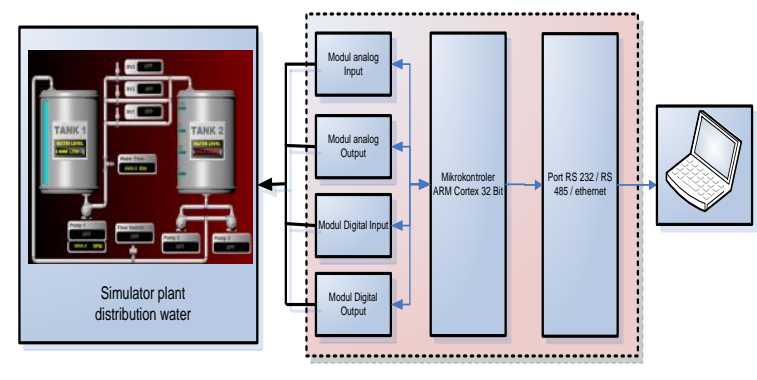

Gambar 5. Implementasi RTU pada simulator

Tahapan penelitian, yaitu:

1. Mendesain dan membuat hardware RTU berbasis mikrokontroler XMC 4500 yang terdiri dari modul IO digital dan analog, komunikasi serial (RS232, RS485, TCP/IP), serta power supply.

2. Mendesain algorithma pengiriman dan penerimaan data melalui komunikasi serial.

3. Melakukan pengujian baik secara hardware maupun software. Pengujian dilakukan untuk mengetahui kemampuan modul I/O dalam mendeteksi status input/output peralatan pada miniatur plant. Indikator keberhasilan dari pengujian ini adalah modul $\mathrm{I} / \mathrm{O}$ dapat mendeteksi status IO peralatan. Selain itu, pengujian dilakukan untuk mengetahui kinerja RTU sebagai pengendali. Indikator keberhasilannya adalah sistem bekerja dengan baik sesuai deskripsi kerja yang diinginkan.

\section{HASIL DAN PEMBAHASAN}

\subsection{Hardware RTU berbasis XMC4500}

Rancangan RTU mempunyai 8 input dan 6 output digital, 3 input dan 2 ouput analog, serta komunikasi serial dan ethernet. I/O ini akan dihubungkan dengan simulator distribusi air. Alamat IO dapat dilihat pada Tabel 1.

Tabel 1. Alamat IO RTU

\begin{tabular}{|c|c|c|c|}
\hline Name & Address Module & Address pin XMC 4500 & \\
\hline Level water sensor & $\mathrm{AIO}$ & P14.0 & \multirow{8}{*}{$\begin{array}{l}\overrightarrow{\check{L}} \\
\text { [ٓ }\end{array}$} \\
\hline Valve 1 & Y02 & P0.6 & \\
\hline Valve 2 & Y04 & P3.4 & \\
\hline Valve 3 & Y05 & P0.7 & \\
\hline Pump 1 (inverter) & $\mathrm{AO} 0$ & P14.8 & \\
\hline Motorize Valve & $\mathrm{AO} 1$ & $\begin{array}{ll}\text { P14.9 } \\
\end{array}$ & \\
\hline Pressure sensor & AI1 & $\begin{array}{l}\text { P14.2 } \\
\end{array}$ & \\
\hline Flow sensor & $\mathrm{AI} 2$ & P14.1 & \\
\hline Level HH (high-high) & $\mathrm{X} 00$ & $\mathrm{P} 0.10$ & \multirow{6}{*}{ 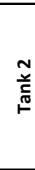 } \\
\hline Level H (High) & $\mathrm{X} 01$ & P0.9 & \\
\hline Level M (medium) & $\mathrm{X} 02$ & P3.1 & \\
\hline Level L (low) & $\mathrm{X} 03$ & P3.0 & \\
\hline Pump 2 & Y00 & P3.2 & \\
\hline Pump 3 & Y01 & $\mathrm{P} 0.2$ & \\
\hline FS (flow switch) & $\mathrm{X} 07$ & $\mathrm{P} 2.15$ & \multirow{6}{*}{ 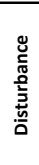 } \\
\hline Reset Buzzer & & P1.15 & \\
\hline Buzzer & Y07 & P1.9 & \\
\hline OL 1 (over load pump 1) & X04 & P2.6 & \\
\hline OL 2 (over load pump 2) & X05 & $\mathrm{P} 2.10$ & \\
\hline OL3 (over load pump 3) & $\mathrm{X} 06$ & $\begin{array}{ll}\mathrm{P} 2.14 \\
\end{array}$ & \\
\hline
\end{tabular}

Dari Tabel 1, $\mathrm{X}$ adalah digital input; $\mathrm{Y}$ adalah digital output; AI adalah analog input; AO adalah analog output.

Hasil pengujian fungsi IO pada modul RTU dapat dilihat pada Gambar 6.

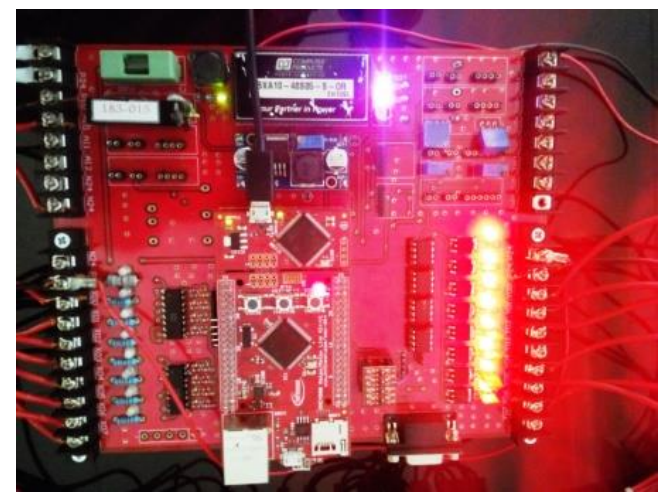

Gambar 6. Hasil uji fungsi IO

Dari Gambar 6, dapat dilihat bahwa semua lampu pada modul RTU menyala. Hal ini mengindikasikan bahwa modul tersebut bekerja dengan baik. Hasil pengukuran tegangan input 
adalah $23,86 \mathrm{~V}$ dan tegangan output 23,81V. Ada selisih sekitar $0,05 \mathrm{~V}$, namun nilai selisih ini kecil sehingga masih diperbolehkan. Untuk pengukuran tegangan input analog adalah 0$10 \mathrm{~V}$, hasil output analog juga sama 0-10V. Output analog ini akan dihubungkan ke inverter untuk men-drive motor pompa 1.

\subsection{Program RTU}

Algoritma untuk read dan write status $\mathrm{IO}$, serta pengiriman dan penerimaan data dari simulator ke modul RTU menggunakan software DAVE 3.10. Data-data ini akan ditampilkan secara real time dalam layar hyperterminal. Tampilan koneksi APP DAVE dan tampilan data pada hyperterminal dapat dilihat pada Gambar 7 dan 8 .
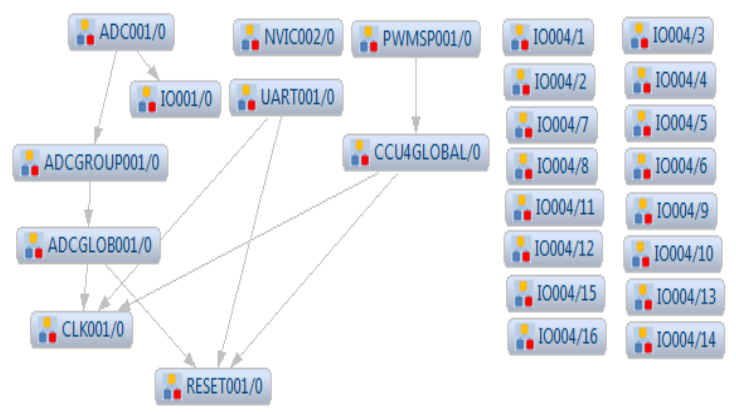

Gambar 7. Koneksi APP DAVE

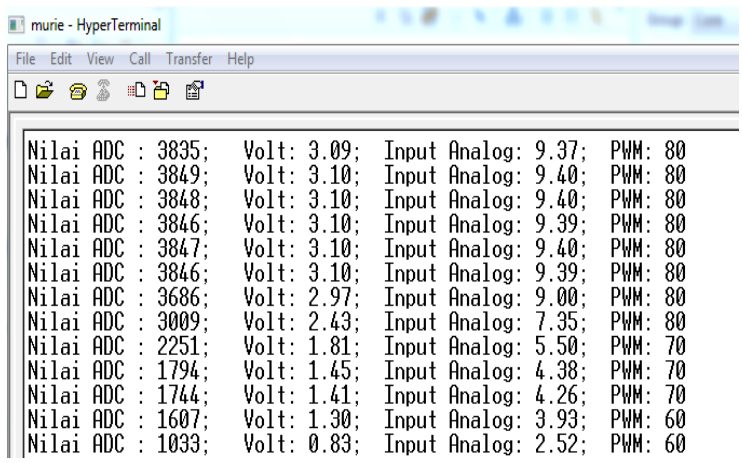

Gambar 8. Tampilan data pada hyperterminal

Dari Gambar 8, dapat dilihat bahwa proses pembacaan, pengiriman, dan penerimaan data berhasil dengan baik. Data dari ADC dibaca oleh mikrokontroler dalam bentuk bilangan integer. Nilai ini dikonversi ke tegangan 0-10V. Output analog menghasilkan PWM (pulse widht modulation) dengan duty cycle 0-100\%.

\subsection{Pengujian RTU sebagai pengendali simulator distribusi air.}

Deskripsi kerja simulator distribusi air dapat dilihat pada Gambar 9. Kecepatan maksimum motor pompa 1 adalah $2900 \mathrm{rpm}$.

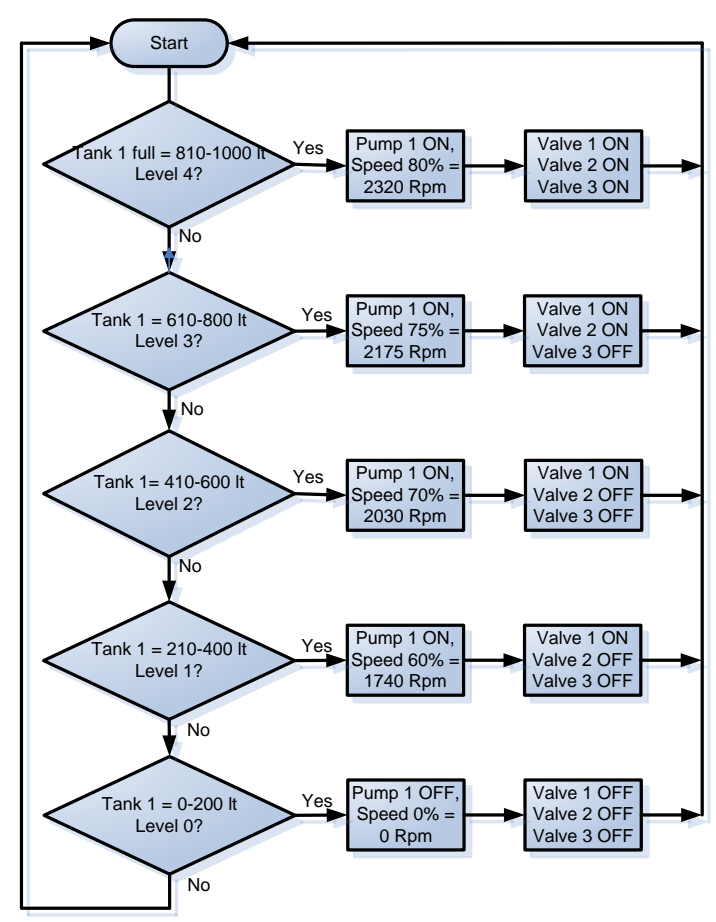

Gambar 9. Flowchart deskripsi kerja simulator distribusi air [8]

Tujuan pengujian ini adalah untuk melihat kinerja RTU sebagai pengendali. Keberhasilan ditandai dengan keseuaian kerja simulator dengn deskripsi yang telah ditentukan. Aktifitas pengujian terlihat pada Gambar 10. Sedangkan hasil pengujian terlihat pada Gambar 11.

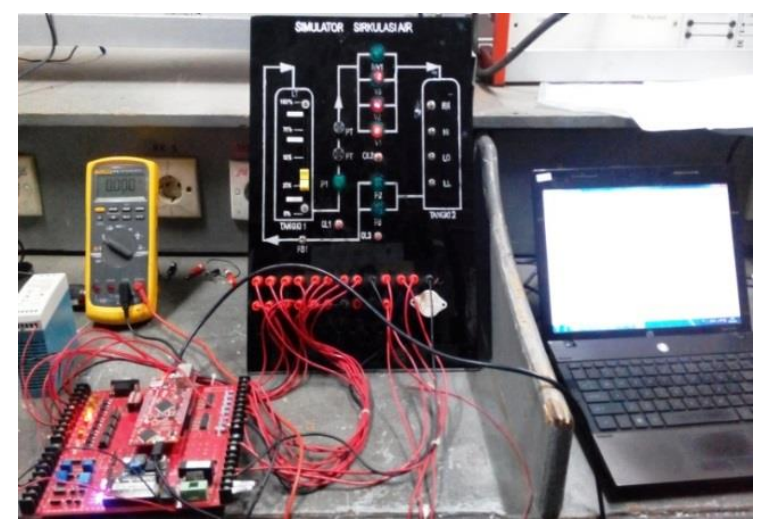

Gambar 10. Aktifitas pengujian 


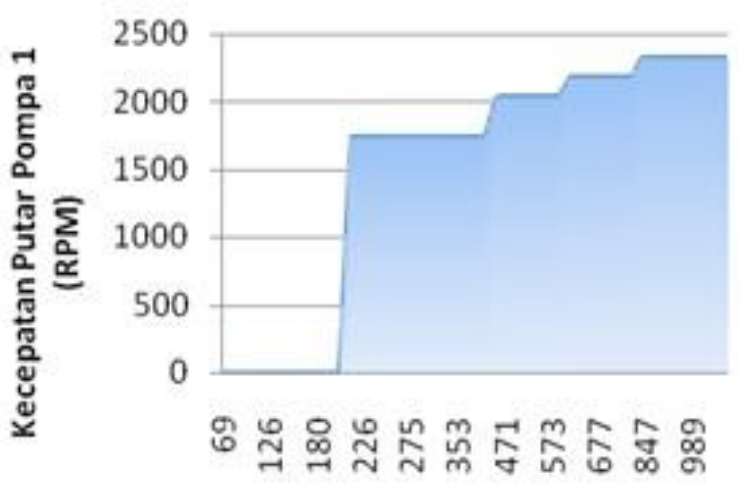

Level Air (Liter)

Gambar 11. Hasil pengujian

Dari Gambar 11, dapat dilihat bahwa kecepatan pompa 1 dibagi dalam 5 level. Ketika tanki 1 penuh sekitar 810-1000 liter, pompa bekerja dengan kecepatan $80 \%$ atau $2320 \mathrm{rpm}$ untuk mengalirkan air. Ketika level air turun di 610-810 liter, kecepatan putar pompa berkurang menjadi $75 \%$ atau $2175 \mathrm{rpm}$. Selanjutnya, jika level air menunjukan nilai 410-600 liter, kecepatan pompa akan berkurang lagi menjadi 2030 rpm. Pada pembacaan level air 210 - 400 liter, pompa akan berputar dengan kecepatan $1740 \mathrm{rpm}$. Akhirnya, jika tangki 1 kosong atau pososi air berada pada 0-200 liter, pompa akan berhenti.

\section{KESIMPULAN}

Prototipe RTU berbasis Arm Cortex 32 bit tipe XMC4500 telah bekerja dengan baik. Hal ini ditandai dengan berfungsinya semua modul IO digital dan analog, modul komunikasi serial dan modul power supply. RTU ini mempunyai 8 input digital dan 8 output digital mosfet, 3 analog input dan 3 analog output. Keberhasilan RTU sebagai pengendali diterapkan pada simulator distribusi air. Hasil pengujian mengindikasikan bahwa prototipe ini telah bekerja dengan baik menggantikan PLC sehingga menawarkan solusi yang berpotensi lebih murah.

\section{DAFTAR PUSTAKA}

[1] Farkhod Alsiherov, Taihoon Kim, Research Trend on Secure SCADA Network Technology and Methods, WSEAS Transactions on System and
Control ISSN: 1991-8763 Issue 8, Volume 5, (2010).

[2] Ahmed, M.M., Ayer Keroh , Soo, W.L. Supervisory Control and Data Acquisition System (SCADA) based customized Remote Terminal Unit (RTU) for distribution automation system, Power and Energy Conference, IEEE 2nd International, p1655 - 1660, (2008).

[3] Purnomo Husnul Khotimah, Dikdik Krisnandi, Design and Implementation of Remote Terminal Unit On Mini Monitoring Weather Station Based on Microcontroller" The 6th International Conference on Telecommunication Systems, Services, and Applications, (2011).

[4] Wael E. Matti, Jabir S. Aziz, Design and Implementation of General Purpose Remote Terminal Unit (R.T.U), Global Journal Electrical and Electronics Engineering, Volume 12 Issue 7, (2012).

[5] David Bailey, Edwin Wright, Practical SCADA for Industry, Elsevier: UK, (2003).

[6] Joseph Yiu, The Definitive Guide to the $A R M{ }^{\circledR}$ Cortex-M3, Elsevier, UK, (2010)

[7] Aung Naing Myint, Hla Soe, Theingi, and Win Khaing Moe, Implementation of Control Unit using SCADA System for Filling System, World Academy of Science, Engineering and Technology Vol:2 2008, p10-25, (2008).

[8] Murie Dwiyaniti, Kendi Moro N, Prototype Sistem Otomasi Berbasis PLC Dan SCADA Network Client Server Dengan Multi Protokol Komunikasi, laporan penelitian, PNJ, (2014)

[9] Arief Wisnu Wardhana, Eka Firmansyah, Addin Suwastono, Perancangan dan Inplementasi Cyclic Redundancy Check16 sebagai Metode Error Cheking pada Transmisi Pesan Protokol Modbus Remote Terminal Unit Berbasis Microcontroller Unit, JNTE Vol 5, No.1: Maret (2016)

\section{Biodata Penulis}

Murie Dwiyaniti, dosen jurusan teknik elektro pada program studi Teknik Otomasi Listrik Industri (TOLI), Politeknik Negeri Jakarta. Penulis telah menyelesaikan program S1 pada Fakultas Teknik Informatika dalam program 
studi Sistem Pengaturan di Institut Teknologi 10 Nopember (ITS) (2000-2002) dan Program S2 Jurusan Teknik Elektro program studi Teknik Kontrol Industri, Universitas Indonesia (20102012).

Kendi Moro Nitisasmita, dosen Jurusan Teknik Elektro pada program studi Teknik Listrik (TL), Politeknik Negeri Jakarta. Penulis telah menyelesaikan program S1 terapan Politeknik Negeri Bandung (Polban) dan Program S2 Jurusan Teknik Komputer di STIMIK ERESHA Jakarta. 